\title{
Efficient wind energy generation within Arctic latitudes
}

\author{
Sergei Kryltcov ${ }^{1}$, and Sergei Solovev ${ }^{1, *}$ \\ ${ }^{1}$ Saint-Petersburg Mining University, Saint-Petersburg, Russia
}

\begin{abstract}
The paper addresses approaches to increasing the efficiency of wind turbines operating in autonomous mode in Arctic regions. Such type of wind turbine operation is related to fluctuations of the generated power, that negatively affects grid power quality. The increase of wind turbines efficiency is achieved by the utilization of current reserve of power converter, which is a necessary part of megawattssized wind energy generation unit. The developed Simulink model of the wind turbines, built according to two of the most suitable for megawatts-level power generation topologies, was used to determine their power output depending on the wind turbine's rotor speed and the wind speed. Obtained power profile was then used to determine the amount of free current reserve depending on the wind speed, which has verified the ability of both wind turbine topologies to efficiently improve grid power quality, therefore leading to reduction or absence of the necessity to install additional power equipment for the compensation purpose.
\end{abstract}

\section{Introduction}

Arctic deposits of fossil fuels play a vital role in ensuring the needs of the modern world in fuel [1]. Since Arctic is a remote territory, energy supply of settlements, drilling and mining sites is provided by autonomous power sources, mainly by diesel generators [2]. Thereby, exploration and development of the Arctic deposits is hardly limited by the cost of consumed diesel fuel and the cost of its transportation to the destination sites, which might be several times higher than the cost of the fuel itself.

Over the last years, it has been shown that use of renewable energy sources to supply the settlements and development sites is a cost-effective solution to the problem of energy generation for remote infrastructure facilities [3]. At the present time, it is not uncommon to supply power for small settlements by the wind, solar or hybrid power systems rated to several to dozens of kilowatts. However, active interest in Arctic exploration leads to the expected addition of megawatts consumed by larger settlements and drilling plants [4].

Wind energy became the most viable solution for the Arctic region, that caused by several factors. As Arctic is located inside the polar circle, it is impossible to generate enough amount of energy during polar night using solar power plants [5]. Bioenergy requires constant supply of biofuel, which is unlikely to be produced on the Arctic territories and is unnecessarily expensive to transport from the mainland. Construction of hydropower and geothermal stations of megawatts size on remote locations are huge projects with significant initial costs and long period of self-sufficiency.

In contrast, dismantled wind turbines (WT) may be relatively easily transported to the remote destination by both water and ground transportation [6]. Average wind speed in Arctic during the year is about 5-6 m/s with reaching $10-12 \mathrm{~m} / \mathrm{s}$ in some areas, which is enough amount to consider WT as effective solution.

However, cold climate and remoteness challenges wind industry to develop the most cost-effective solutions for the Arctic regions. Grids, powered by autonomous sources, more often require additional power devices to be installed to maintain sufficient power quality for consumers, that leads to significant additional expenses for not only power generation, but also its distribution. The paper is devoted to reduction of the construction and maintenance costs for additional compensators for operating in autonomous mode megawatts-sized WTs, which is achieved by utilization of their current reserve to maintain necessary grid power quality.

\section{Methods}

As the previous researches showed, suitability of Arctic regions for wind energy generation force the extensive interest of scientific communities and manufacturing companies in overcoming following problems [7-10].

1. Low temperatures. As average January temperature on the Arctic territory range from $-34{ }^{\circ} \mathrm{C}$ to $0{ }^{\circ} \mathrm{C}$, whole WT equipment should be able to operate at low temperatures. That includes necessary heating of both mechanical and power equipment, use of

* Sergei Solovev: forsakenfour@gmail.com 
cold-resistant lubricants for moving and rotating mechanisms and cold-resistant alloys for exposed parts.

2. Rotor blades icing. Occurring on the rotor blades icing represents one of the most severe problem, reducing WT efficiency [11]. On the one hand, rotor blades should be designed in appropriate way to survive regular icing, which in Arctic can occur up to $20 \%$ of the time during the year. On the other hand, efficiency of power generation significantly suffers from the blades icing, therefore requiring solutions for icing detection and removal.

3. Remoteness of the Arctic territories. To install WT capacities to the Arctic infrastructure facilities, at first, they should be delivered to the destination. That requires manufacturers to use light-weight materials that are still durable at low temperatures. At the same time, necessity to provide significant generation capacities to the remote sites challenges manufacturers to balance the size of WTs, as their power output mainly depends on the rotor size of the WT.

4. Power quality. As WTs will operate in autonomous mode, generated power will constantly fluctuate, affecting grid voltage quality [12]. In order to deliver power with necessary quality for consumers, it is essential to install additional compensation devices.

The paper is devoted to solution of problem with power quality of wind energy generation in Arctic regions.

Efficiency of the WT output consists of efficiency of energy conversion processes during power generation. The greatest influence on WT efficiency is exerted by the aerodynamical conversion process, as maximum kinetic energy of the ongoing air mass can be transformed to the mechanical power of the WT shaft only at a specific ratio between the WT rotor speed and wind speed. Algorithms, that maintain following this ratio, are called maximum power point tracking (MPPT) algorithms [13, 14].

In order to achieve MPPT operation of the WT, the control of rotor speed is required. Rotor speed alteration is achieved by the use of power converters when connecting generator to the grid. Currently, two main concepts of megawatts-sized WT are available at the wind energy market: WT with generator, connected to the grid via full-rated power converter, and WT with doubly fed induction generator (DFIG). Both concepts are proven to be efficient solutions and are explained in following subsections.

\subsection{Wind turbines with full-rated back-to-back power converter}

The topology of WT with full-rated power converter is shown in the Fig. 1. The generator is typically implemented as synchronous generator on permanent magnets (PMSG). The gearbox is used to transform lowspeed rotation of the WT shaft to high-speed rotation of generator shaft. However, increase of the number of poles for synchronous generator may make gearbox unnecessary component. PMSG stator is connected to the grid via back-to-back converter - two power inverters sharing same DC-link.

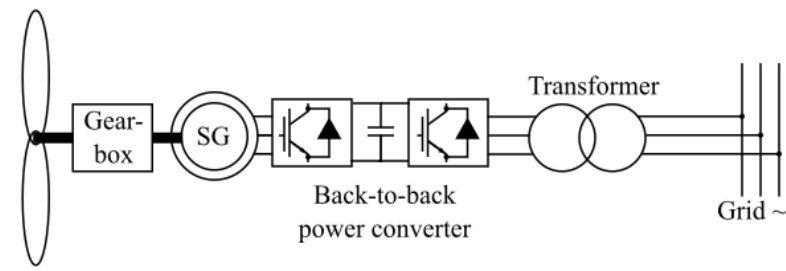

Fig. 1. Wind turbine built according to the PMSG topology

The DC-link allows to decouple AC power circuits of the grid and generator, therefore acting as buffer between grid and PMSG. Inverter at the rotor side allows to produce currents of arbitrary form (frequency and amplitude is usually altered) providing ability to control rotor speed, therefore extracting the maximum power from the air flow or limiting it output vice versa. DC-link existence leads to smoothing of power fluctuation in WT power circuits, therefore reducing stresses in mechanical and electrical parts of the WT. Inverter at the grid side allows to independently control active and reactive power transmitted to the grid. The main drawback of such topology is high cost of power converters and higher losses in its circuits, especially on IGBT-modules and output filter.

\subsection{Wind turbines with doubly-fed induction generator}

Topology of the WT with DFIG is shown in the Fig. 2. DFIG concept utilizes induction generator (IG) with wound rotor. The three-winding transformer is used to connect IG to the grid. IG stator is connected directly to the one set of transformer windings, IG rotor in turn is connected to another set of transformer windings via back-to-back power converter.

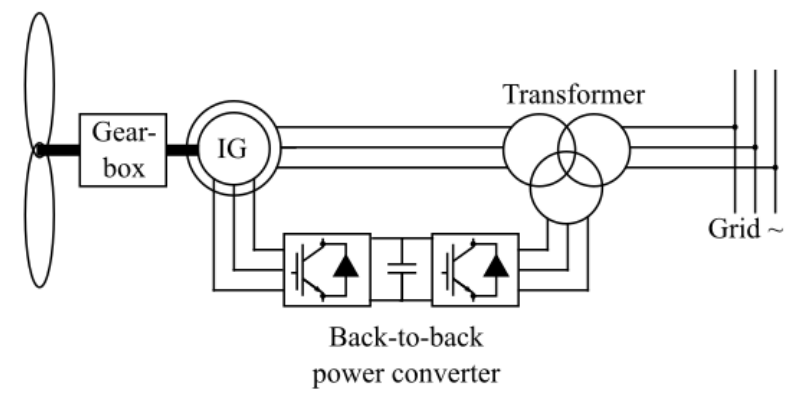

Fig. 2. Wind turbine built according to the DFIG topology

Rotor speed is controlled by the power inverter at the rotor side, which is connected to the IG using slip rings. That is the main disadvantage of the concept leading to much higher DFIG maintenance cost compared with PMSG. However, to achieve dynamics and control range of the WT with PMSG, the power flow in rotor circuit will not exceed $25-30 \%$ of overall WT power output, which causes the primary advantage of DFIG topology lower size of the power converter. Therefore, WT with 
DFIG has lower initial cost and magnetizing and thermal losses in power converter compared to the WT with PMSG, however it has higher maintenance cost because of the slip rings. That makes the choice between the topologies unobvious, requiring balancing between the initial costs of the WT construction and the period of its self-sufficiency [15-17].

\section{Results and Discussion}

The WT output power depends on the ratio between cubic wind speed applied to the WT rotor blades and rotor speed [18]. The computer model of $2 \mathrm{MW}$ WTs suited for nominal wind speed up to $12 \mathrm{~m} / \mathrm{s}$ was developed in MATLAB/Simulink environment to determine the active power load of the WT depending on both wind and rotor speeds. Obtained output power profiles of both WT concepts match exactly, therefore WT power profile is shown in the Fig. 3.

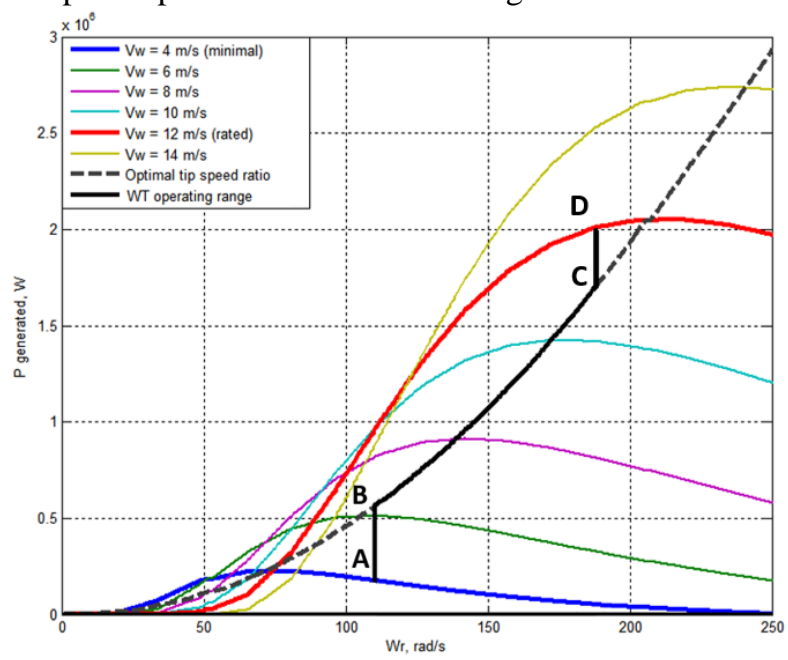

Fig. 3. Obtained power profile of WT during its operation on different wind speeds

At the point A the WT has been synchronized to the grid as minimal wind speed level is achieved. This corresponds to the minimal power output of the WT. AB segment of the curve corresponds to WT working under low wind speeds, therefore extracted power from the air flow is not maximum, as rotor speed remains below optimal level at its lowest value specified by the maximum slip value of generator. At the point $B$ the optimal ratio between the rotor and wind speed is achieved. Between points B and C WT operates according to MPPT, providing maximum extraction of the power from the oncoming air mass. At the point $\mathrm{C}$ MPPT operation ends, as WT reaches maximum rotor speed level. Segment CD corresponds to torque control operation of the WT, where converter uses available current reserve to increase power output level. At the point $\mathrm{D}$ the nominal output power level is achieved. Further increase of wind speed below cut-off level will lead to maintaining rated output power using pitch angle control of the blades, which allows to reduce the aerodynamic conversion efficiency of the WT.

As it is shown in the Fig. 3, on the wind speeds under the nominal value the WT power output significantly decreases as well as the load of power converter. However, free current reserve of the power converter may be used to improve the grid voltage quality or provide ride-through support during fault events in the grid. Within PMSG topology, whole power flows through back-to-back converter. The grid-side inverter may apply currents of arbitrary form to the grid, therefore providing ability to improve grid voltage quality by the following factors:

- voltage stabilization;

- power factor control;

- asymmetry correction;

- harmonics compensation;

- voltage sag ride-through support.

The efficiency of the WT operating for grid voltage improvement strongly depends on the available current of the grid-side inverter.

In case of the DFIG, the grid-side inverter is rated only to $25-30 \%$ of the output power, which degrades its ability to affect grid voltage quality. However, rotor-side inverter may be used to alter IG magnetizing, providing control of reactive power exchange between the IG stator and grid. Therefore, WT with DFIG may be efficiently used to stabilize grid voltage and maintain power factor control, while it is not effective for asymmetry and harmonics compensation compared to the PMSG topology of the WT.

To verify possibility of using WT for grid voltage quality improvement, the current reserve of both WT topologies was estimated using computer simulation. During the simulation, converter was following the reference to exchange maximum amount of reactive power with the grid, depending on its active load by the generated power. Results of simulation are shown in the Fig. 4.

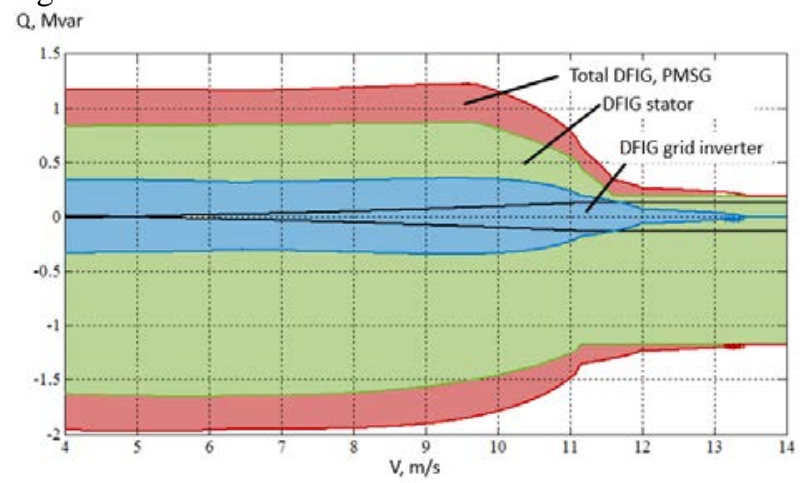

Fig. 4. Reactive power reserve of the WT

As it is shown in the Fig. 4, the WT may be effectively used to improve grid voltage quality on the winds speed below rated, which may occur up to half of the total operational time of the WT. As grids powered by only autonomous energy sources require installation of additional compensation devices to provide required power quality for consumers, considered operation of WTs could reduce costs of construction and maintaining of additional equipment. Moreover, depending on the severity of the grid voltage distortions, WTs generated power may be artificially limited below rated level to 
provide necessary grid voltage quality by one or more factors.

\section{Conclusion}

In the paper, main challenges to the wind energy generation for Arctic regions were indicated. The work is devoted to solving the problem of maintaining necessary power quality for the consumers, when wind turbines operate in autonomous mode, which is the only option for Arctic. Developed computer model was used to verify that two main topologies of the wind turbines, suitable for effective power generation of megawatts levels, at the wind speeds below rated have significant capabilities for improvement of the grid voltage quality by following factors: voltage magnitude, power factor, harmonics distortion, voltage imbalance. Still, at wind speeds equal or above rated, wind turbines power output may be artificially reduced by the breaking or pitch angle control of the rotor blades, therefore freeing current of power converter to maintain necessary power quality. Utilization of the wind turbines for power quality improvement may lead to absence of necessity to install additional power compensators, therefore reducing costs of construction and maintenance of the generation system.

\section{References}

1. L. Schirrmeister, G. Grosse, S. Wetterich, P. P. Overduin, J. Strauss, E. A. Schuur, H. W. Hubberten, Fossil organic matter characteristics in permafrost deposits of the northeast Siberian Arctic. Journal of Geophysical Research: Biogeosciences, 116(G2)(2009)

2. M. Torres, L. A. Lopes, Virtual synchronous generator control in autonomous wind-diesel power systems. In Electrical Power \& Energy Conference (EPEC), IEEE, 1-6 (2009)

3. A. B. Kanase-Patil, R. P. Saini, M. P. Sharma, Integrated renewable energy systems for off grid rural electrification of remote area. Renewable Energy, 35(6), 1342-1349 (2010)

4. R. Redlinger, P. Andersen, P. Morthorst, Wind energy in the 21st century: Economics, policy, technology and the changing electricity industry. Springer (2016)

5. J. Sedlar, M. Tjernström, T. Mauritsen, M. D. Shupe, I. M. Brooks, P. O. G. Persson, M. Nicolaus, (2011). A transition-ing Arctic surface energy budget: the impacts of solar zenith angle, surface albedo and cloud radiative forcing. Climate dynamics, 37(7-8), 1643-1660 (2011)

6. E. Uraz, Offshore Wind Turbine Transportation \& Installation Analyses Planning Optimal Marine Operations for Offshore Wind Projects, Master Thesis, 65 (2011)

7.E. Martínez, F. Sanz, S. Pellegrini, E. Jiménez, J. Blanco, Life-cycle assessment of a 2-MW rated power wind turbine: CML method. The International Journal of Life Cycle Assessment, 14(1), 52 (2009)
8. V.Ya. Frolov, D.V. Ivanov, Calculation of a plasma composition and its thermophysical properties in cases of maintaining or quenching of electric arcs, Journal of Physics: Conference Series J. Phys: Conf. Ser. 1058 012040, 1-6 (2018)

9. V. Y. Frolov, Neelov A. A., Zhiligotov R. I. and Bystrov A. V. Identification of the protection parameters of the local electrical network taking into account the detuning of the inrush current, 2018 IEEE Conference of Russian Young Researchers in Electrical and Electronic Engineering (EIConRus), Moscow, 626-628 (2018)

10. R. Kozakov, A. Khakpour, S. Gorchakov, D. Uhrlandt, D. Ivanov, I. Murashov, G. Podporkin, V. Frolov, Investigation of a Multi-Chamber System for Lightning Protection at Overhead Power Linesm, Proc. of 21st Symposium on Physics of Switching arc, 150154 (2015)

11. L. Makkonen, T. Laakso, M. Marjaniemi, K. J. Finstad, Modelling and prevention of ice accretion on wind turbines. Wind Engineering, 25(1), 3-21 (2001)

12. H. S. Ko, G. G. Yoon, W. P. Hong, Active use of DFIG-based variable-speed wind-turbine for voltage regulation at a remote location. IEEE Transactions on Power Systems, 22(4), 1916-1925 (2007)

13. E. Koutroulis, K. Kalaitzakis, Design of a maximum power tracking system for wind-energyconversion applications. IEEE transactions on industrial electronics, 53(2), 486-494 (2006)

14. A. Budin, M. Pinchuk, V. Leontev, A. Leks, N. Kurakina, A. Kiselev, J. Simakova, V. Frolov, Experimental Stand for Investigations of Insulator Degradation and Electrode Erosion in High-current Breaker. Plasma Physics and Technology 4, 120-123 (2017)

15. C. H. Ng, M. A. Parker, Li Ran, P. J. Tavner, J. R. Bumby, E. Spooner, A Multilevel Modular Converter for a Large, Light Weight Wind Turbine Generator, IEEE Trans. Power Electron., 23(3), 10621074, (2008)

16. L. Ertao, X. Yin, Z. Zhang, Y. Chen, «An Improved Transformer Winding Tap Injection DSTATCOM Topology for Medium-Voltage Reactive Power Compensation», IEEE Trans. Power Electron., 11, (2017)

17. N. M. Salgado-Herrera, A. Medina-Rios, R. Tapia-Sanchez, и O. Anaya-Lara, «Reactive power compensation through active back to back converter in type-4 wind turbine», proc of IEEE International Autumn Meeting on Power, Electronics and Computing (ROPEC), 1-6, (2016)

18. M. Perrow, Wildlife and Wind Farms Conflicts and Solutions, 3, Offshore: Potential Effects (2019) 